\title{
Aspectos clínico-patológicos e laboratoriais do envenenamento crotálico experimental em bovinos ${ }^{1}$
}

\author{
Flávio A.S. Graça ${ }^{2}$, Paulo V. Peixoto ${ }^{3}$, Cleide D. Coelho², Saulo A. Caldas ${ }^{2}$ e \\ Carlos Hubinger Tokarnia ${ }^{3}$
}

\begin{abstract}
Graça F.A.S., Peixoto P.V., Coelho C.D., Caldas S.A. \& Tokarnia C.H. 2008. [Clinical and pathological aspects of experimental Crotalus poisoning in cattle.] Aspectos clinicos e patológicos do envenenamento crotálico experimental em bovinos. Pesquisa Veterinária Brasileira 28(6):261-270. Projeto Sanidade Animal Embrapa/UFRRJ, Seropédica, RJ 23890-000, Brazil. E-mail: flaviograca @uol.com.br

Crotalus poisoning was experimentally reproduced by subcutaneous inoculation of Crotalus durissus terrificus (South American rattlesnake) venom into 10 clinically healthy mixed bred 12 to 36 -month-old cattle, weighing 125 to $449 \mathrm{~kg}$. Two animals were used as controls. The animal that received a dose of $0.03 \mathrm{mg} / \mathrm{kg}$ body weight died $7 \mathrm{~h} 40 \mathrm{~min}$ after inoculation. A $0.015 \mathrm{mg} / \mathrm{kg}$ dose provoked death in 4 out of 7 young oxen. Two animals given $0.0075 \mathrm{mg} / \mathrm{kg}$ became slightly sick and recovered. Onset of symptoms occurred from $1 \mathrm{~h} 30 \mathrm{~min}$ to $13 \mathrm{~h} 45 \mathrm{~min}$ after inoculation. The clinical course varied from $5 \mathrm{~h} 25 \mathrm{~min}$ to $45 \mathrm{~h}$ for animals that died, and from $33 \mathrm{~h} 15 \mathrm{~min}$ to 17 days for animals that recovered. The main nervous signs observed were diminished response to external stimuli, hypotonic reflexes, dragging of the hooves, apathy, difficulties in moving around obstacles, ocular globe paralysis, lateral and sternal decubitus, and tongue paralysis. Adipsia and sometimes petechiae in the conjunctival and vaginal mucosa were observed. A slight to moderate increase in bleeding time was noted in 6 animals, and a moderate increase in partial thromboplastin time was found in 7 others. Moderate leukocytosis with neutrophilia, relative lymphopenia, eosinopenia, and monocytosis was found. There was a significant increase in creatine kinase serum levels of a ten-fold order. No significant alterations were revealed by urinalysis. Necropsy revealed minimal edema at the inoculation site, few petechiae and equimoses in the epicardium, omentum, biliary vesicle and bladder mucosa of some animals. Histopathological examination revealed necrosis (hyalinization) of groups or isolated myocytes in different muscles examined, both near and far from the inoculation site, in all animals. The diagnosis of Crotalus poisoning and its differentiation from diseases causing paralysis and muscular necrosis in cattle in Brazil are discussed.
\end{abstract}

INDEX TERMS: Poisoning, Crotalus durissus terrificus, cattle, snake bite.

RESUMO.- Reproduziu-se experimentalmente o envenenamento crotálico, através da inoculação, por via subcutânea, do veneno de Crotalus durissus terrificus (casca-

\footnotetext{
${ }^{1}$ Recebido para em 23 de março de 2007.

Aceito para publicação em 27 de dezembro 2007.

Parte da Tese de Doutorado do primeiro autor, defendida na Universidade Federal Rural do Rio de Janeiro (UFRRJ).

2 Curso de Pós-Graduação em Ciências Veterinárias, Área de Concentração em Sanidade Animal, UFRRJ, Seropédica, RJ 23890-000, Brasil. *Autor para correspondência: flaviograca@uol.com.br

${ }^{3}$ Departamento de Nutrição Animal e Pastagem, Instituto de Zootecnia, UFRRJ, Seropédica, RJ. E-mails: peixotop@ufrrj.br, tokarnia@ufrrj.br
}

vel sul-americana) em dez bovinos mestiços. Dois animais foram utilizados como controle. O bovino que recebeu dose de $0,03 \mathrm{mg} / \mathrm{kg}$ de peso corporal, morreu $7 \mathrm{~h} 40 \mathrm{~min}$ após a inoculação. A dose de $0,015 \mathrm{mg} / \mathrm{kg}$ causou a morte em quatro de sete bovinos inoculados, enquanto os dois animais que receberam $0,0075 \mathrm{mg} / \mathrm{kg}$ adoeceram discretamente e se recuperaram. Os sintomas tiveram início entre $1 \mathrm{~h} 30 \mathrm{~min}$ e $13 \mathrm{~h} 45 \mathrm{~min}$ após a inoculação. A evolução oscilou entre $5 \mathrm{~h} 25 \mathrm{~min}$ e $45 \mathrm{~h}$ para os animais que morreram e entre $33 \mathrm{~h} 15 \mathrm{~min}$ e 17 dias entre os animais que se recuperaram. Os principais sinais nervosos observados foram diminuição da resposta aos estímulos 
externos, reflexos hipotônicos, arrastar dos cascos no solo, aparente apatia, paralisia do globo ocular e da língua, decúbito esternal e lateral. Verificaram-se também adipsia e, por vezes, petéquias nas mucosas vaginal e conjuntival. Houve discreto a moderado aumento do tempo de sangramento e moderado aumento do tempo de tromboplastina parcial ativada. Houve moderada leucocitose com neutrofilia, linfopenia relativa, eosinopenia, monocitose e discreto aumento do número de bastões. Foi evidenciado significativo aumento dos níveis séricos de creatinaquinase, contudo, não foram observadas alterações significativas através da urinálise. À necropsia constataram-se edema quase imperceptível no local da inoculação, discretas petéquias e sufusões no epicárdio, omento, vesícula biliar e mucosa da bexiga em alguns dos animais envenenados experimentalmente. Os exames histopatológicos revelaram necrose (hialinização) de grupos de miócitos ou em miócitos isolados em dez diferentes músculos esqueléticos examinados, próximos ou distantes do local de inoculação em todos os animais necropsiados. Concluí-se que o envenenamento por Crotalus Sul-americanas em bovinos não cursa com mioglobinúria e que o quadro marcado de paralisia flácida mimetiza o observado no botulismo. Adicionalmente foram feitas observações sobre o diagnóstico do envenenamento crotálico e sua diferenciação com enfermidades que cursam com paralisia e necrose muscular em bovinos do Brasil.

TERMOS DE INDEXAÇÃO: Envenenamento, Crotalus durissus terrificus, bovino, acidente ofídico.

\section{INTRODUÇÃO}

Segundo alguns autores, os acidentes ofídicos seriam muito freqüentes e determinariam pesadas perdas econômicas aos pecuaristas no Brasil. Fazendeiros, vaqueiros e também veterinários de campo, de uma maneira geral, acreditam que as picadas-de-cobra constituem uma causa muito freqüente de morte de animais de fazenda mas, segundo Pacheco \& Carneiro (1932), o homem do campo tem uma tendência inata e equivocada a atribuir à intoxicação por plantas e aos envenenamentos ofídicos, a maioria das "mortes súbitas" em bovinos.

Em levantamento recente, Tokarnia \& Peixoto (2006) questionaram essa pretensa importância que os envenenamentos ofídicos teriam como causa de morte de bovinos no país.

A espécie Crotalus durissus terrificus habita os cerrados do Brasil central, as regiões áridas e semi-áridas do Nordeste, os campos e áreas abertas no Sul, Sudeste e Norte (Melgarejo 2003). Na Região Sudeste vem sendo apontada como invasora em municípios da região sul do Estado do Rio de Janeiro, dada a sua considerável capacidade de adaptação e dispersão; esse fenômeno devese ao intenso desmatamento para a implantação de pastagens (Bastos et al.2005).

Contudo, não há relatos científicos de casos naturais de acidentes por Crotalus em bovinos no Brasil. Quase tudo que se sabe sobre a ação do veneno de serpentes desse gênero e sobre o correspondente quadro clínicopatológico do envenenamento crotálico em bovinos, se baseia na experimentação (Araújo et al. 1963, Belluomini et al. 1982, Lago 1996, Bicudo 1999, Tokarnia \& Peixoto 2006).

Em bovinos envenenados pela peçonha das Crotalus sul-americanas há, de acordo com esses autores, ausência de necrose aparente no local da inoculação, dificuldade de locomoção, andar cambaleante e incoordenação motora, além de decúbito esternal e abdominal lateral de 6-48 horas acompanhados de fenômenos subjetivos de dor, parestesia local, torpor, obnubilação, imobilidade do globo ocular com reflexos palpebrais normais, apatia, letargia profunda, mioclonias, diminuição do tônus muscular, diminuição de reflexos superficiais, incoordenação motora, ausência de hemoglobinúria, micções normais, sialorréia, anorexia, adipsia, timpanismo, dificuldade de eructação por decúbito, hipotonia ruminal, perda de sensibilidade à dor "profunda", paralisia flácida, dispnéia pela dificuldade de contração dos músculos da respiração e morte. Belluomini et al. (1982) observaram ainda, quando se rotaciona a cabeça do animal na direção latero-caudal, que a esclera não fica exposta, ou fica apenas parcialmente exposta, porque há paralisia dos músculos responsáveis pela movimentação do globo ocular.

A necropsia de 16 bovinos inoculados experimentalmente com $0,05 \mathrm{mg} / \mathrm{kg}$ de veneno de $C$. durissus terrificus, dos quais 12 foram submetidos à soroterapia, revelou alterações congestivo-hemorrágicas em todos os órgãos (Saliba et al. 1983). Ao exame microscópico haveria necrose hialina nas paredes das arteríolas, miocárdio e no fígado. Nos rins ocorreriam alterações proeminentes, desde degeneração hidrópica até necrose tubular com o aparecimento de cilindros hialinos e albumina no espaço intra-capsular (Saliba et al. 1983). Bovinos submetidos ao envenenamento na dose de $0,03 \mathrm{mg} / \mathrm{kg}$ apresentaram pequeno edema transitório foi observado no local da inoculação, moderado aumento do tempo de coagulação sangüínea, leucocitose, hipofibrinogenemia e aumento da concentração sérica de uréia em $23 \%$ e de creatinaquinase em $66 \%$. As alterações anátomo-histológicas consistiram em leves hemorragias nos pulmões, intestinos, músculos, e em maior intensidade, no coração enquanto nos músculos esquelético e cardíaco havia degeneração hialina, vacúolos e infiltrados celulares (Lago 1996).

Esse estudo objetiva aprofundar o conhecimento sobre a natureza do envenenamento crotálico em bovinos, no intuito de melhor caracterizá-lo.

\section{MATERIAL E MÉTODOS}

O experimento foi realizado entre maio de 2003 e janeiro de 2005 nas instalações do Projeto Sanidade Animal do Convênio Embrapa//UFRRJ e submetido à Comissão de Ética do Curso de Pós-Graduação em Ciências Veterinárias da UFRRJ.

Foram utilizados 12 bovinos mestiços, clinicamente sadios, sendo 5 fêmeas e 7 machos, com peso variando entre os 125 e 


\section{Quadro 1. Envenenamento crotálico experimental em bovinos. Principais dados sobre o delineamento experimental e} desfecho

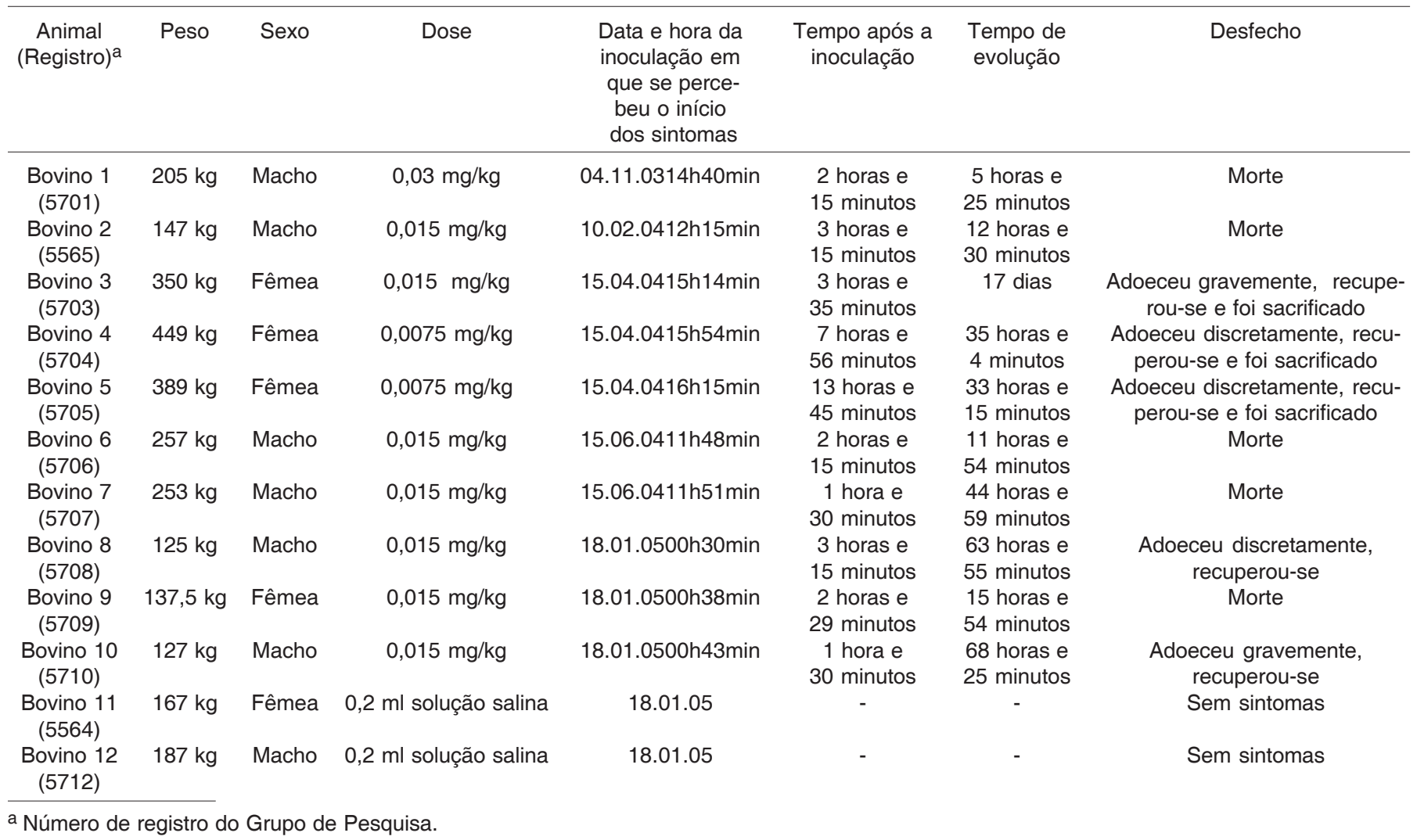

$449 \mathrm{~kg}$ e idade entre 12 e 36 meses (Quadro 1). A inoculação do veneno, diluído em solução fisiológica a $10 \mathrm{mg}$ por $\mathrm{ml}$, foi feita no terço superior da região glútea, por via subcutânea; a agulha era protegida por um dispositivo plástico que garantia a inoculação na profundidade de $6 \mathrm{~mm}$ (modificação da técnica utilizada por Belluomoni 1972). Foram realizados exames clínicos gerais e neurológicos a cada duas horas até a morte ou a recuperação do animal, além de coletas de sangue dos animais imediatamente antes e depois de 6, 12, 24 e 48 horas após a inoculação.

As coletas de urina foram realizadas por micção espontânea durante o exame clínico e por punção vesical durante a necropsia.

Quatro dos seis animais que não vieram a óbito foram eutanasiados com thiopental sódico por via intra-venosa na dose de $20 \mathrm{mg} / \mathrm{kg}$. Todos os bovinos foram necropsiados imediatamente após a morte ou eutanásia. Foram coletados fragmentos de fígado, vesícula biliar, rins, baço, tecido subcutâneo e pele do local da inoculação e área contra-lateral, linfonodos submandibulares, parotídeos, retrofaríngeos, pré-escapulares, mediastínicos, mesentéricos, inguinais e poplíteos além de glândulas salivares, pâncreas, adrenal, bexiga, intestinos delgado e grosso, rúmen, retículo, omaso, abomaso, pulmões, coração, testículo ou ovário, encéfalo, medula, junção costocondral, tireóide, hipófise, globo ocular, além dos seguintes músculos estriados: masseter, língua, cervical, longíssimo dorsal, diafragma, intercostal, bíceps, psoas, semitendináceo e semimembranáceo do membro inoculado e contra-laterais. Os fragmentos foram colhidos e fixados em formalina $15 \%$, para exames histológicos.

Após a fixação em formalina a 15\%, os fragmentos, proces- sados manualmente, foram desidratados em álcool absoluto, tratados com xilol, embebidos e incluídos em parafina, cortados na espessura 5 micrômetros e corados pela Hematoxilina e Eosina (HE), para serem posteriormente analisados em microscópio óptico.

\section{RESULTADOS}

\section{Dose letal e evolução}

Nos animais que receberem doses potencialmente letais $(0,03$ e $0,015 \mathrm{mg} / \mathrm{kg})$, as primeiras alterações de comportamento foram evidenciadas a partir de uma hora e 30 minutos após a inoculação. Os dois bovinos que receberam as menores doses $(0,0075 \mathrm{mg} / \mathrm{kg})$, apresentaram quadro discreto de diminuição da resposta aos estímulos e reflexos hipotônicos evidenciados a partir das 7 horas 56 minutos e 13 horas 45 minutos pós-inoculação que desapareceu aos poucos, respectivamente, com 33 horas 15 minutos e 35 horas 4 minutos.

O bovino que recebeu a dose de $0,03 \mathrm{mg} / \mathrm{kg}$ apresentou evolução clínica muito rápida (5 horas 25 minutos). A dose de $0,015 \mathrm{mg} / \mathrm{kg}$ foi, dentre as que causaram óbito, a que levou a uma evolução mais longa e possibilitou meIhor observação dos achados clínicos, de necropsia e laboratoriais, porém só causou a morte de quatro dos sete animais inoculados. Os bovinos que receberam esta dose e morreram, apresentaram uma evolução mínima de 11 horas 54 minutos e máxima, de 44 horas 59 minutos. 0 
período mínimo de evolução dentre os animais que se recuperaram após receber a mesma dose, foi de 64 horas e no máximo, de 17 dias.

A dose de $0,0075 \mathrm{mg} / \mathrm{kg}$ não provocou a morte, mas os animais inoculados apresentaram discretas alterações tanto no comportamento, como nos exames de patologia clínica. Nesses animais, o tempo de evolução foi observado até a remissão dos sintomas, a qual ocorreu entre 33 e 35 horas após início do quadro clínico. (Quadro 1)

\section{Quadro clínico geral}

Em todos os animais foi observada adipsia após o início dos sintomas, porém o apetite era mantido, enquanto os movimentos de apreensão e mastigação ainda não estavam comprometidos. Após a paralisia dos músculos da face, alguns animais demonstravam interesse pelo alimento mesmo diante da incapacidade em apreendê-los. As mensurações da temperatura, freqüências cardíaca e respiratória se mantiveram dentro dos parâmetros fisiológicos durante toda a evolução clínica. Todos os animais apresentaram ausculta cardíaca normal, mesmo na fase final da evolução clínica. À ausculta respiratória, verificou-se dispnéia mista, à medida que o quadro se agravava, porém sem alteração da freqüência.

No exame das mucosas, os Bovinos 2 e 3 apresentaram algumas petéquias, respectivamente, nas mucosas conjuntival e vaginal, que desapareceram no Bovino 3, com cinco dias após a inoculação. Após o decúbito, a compressão abdominal gerava uma condição desconfortável para os animais que, além de apresentarem timpanismo secundário, intensificava a dispnéia mista.

\section{Quadro neurológico}

A primeira alteração observada era o arrastar das pinças seguido pela discreta diminuição da resposta aos estímulos externos, que se evidenciava pela redução do raio de aproximação e a permissão do contato manual. Na fase

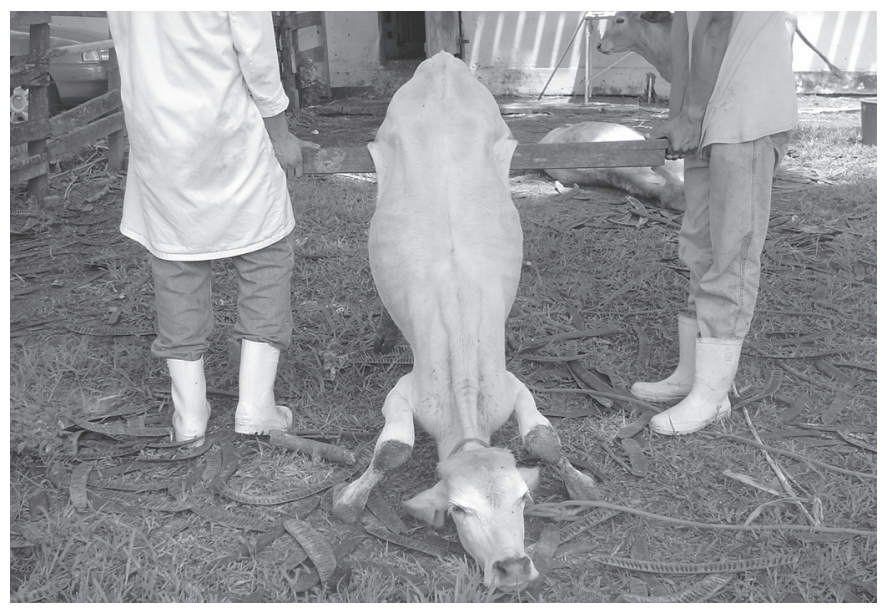

Fig.1. Diminuição do tônus muscular, caracterizado no teste de apóio somente com os membros posteriores na "prova de suspensão dos membros posteriores", no envenenado com a toxina de Crotalus durissus terrificus (Bovino 10). seguinte foi observada diminuição gradual do tônus muscular, caracterizada pela dificuldade em transpor obstáculos ou no teste de apoio só com os membros torácicos "prova de suspensão dos membros posteriores" ou ainda, durante a contenção dos animais (Fig.1). Neste período era notada progressiva hipotonia nos músculos da cabeça, alguns animais com discreta exposição da ponta da língua entre os lábios e sialorréia. Com o agravamento da hipotonia muscular, os animais se colocavam em decúbito esternal e não conseguiam se levantar, mesmo quando estimulados, mas alguns ainda sustentavam a cabeça e o pescoço. A resposta à avaliação de sensibilidade cutânea

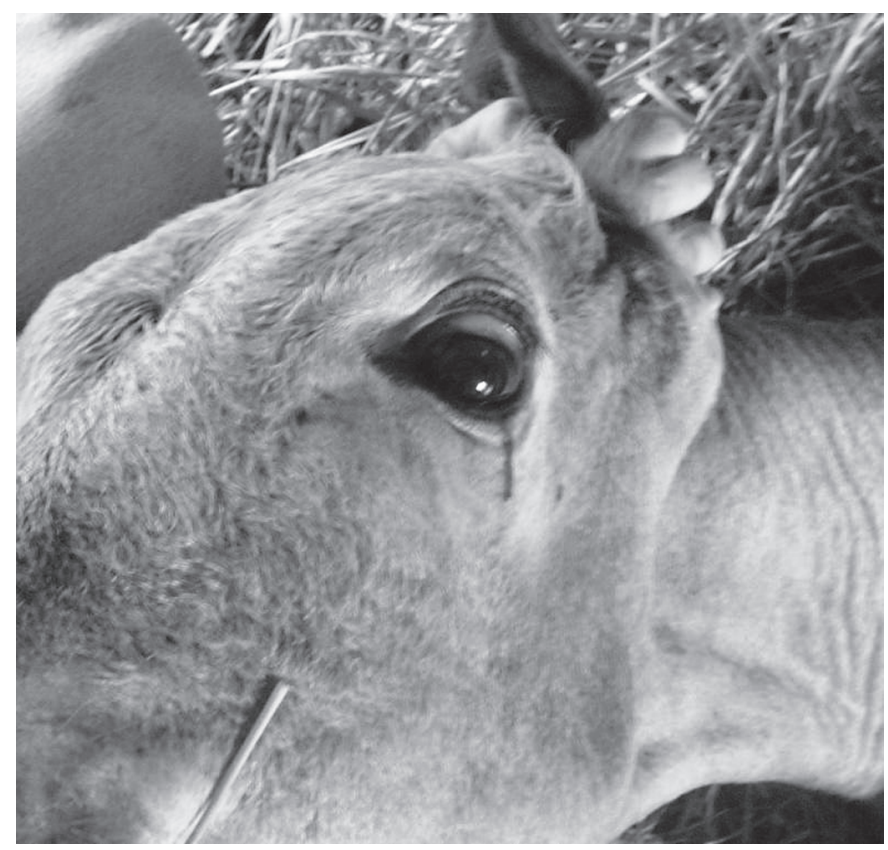

Fig.2. Paralisia do globo ocular quando se rotacionava a cabeça na direção latero-caudal através da verificação da exposição parcial da esclera (Bovino 10).

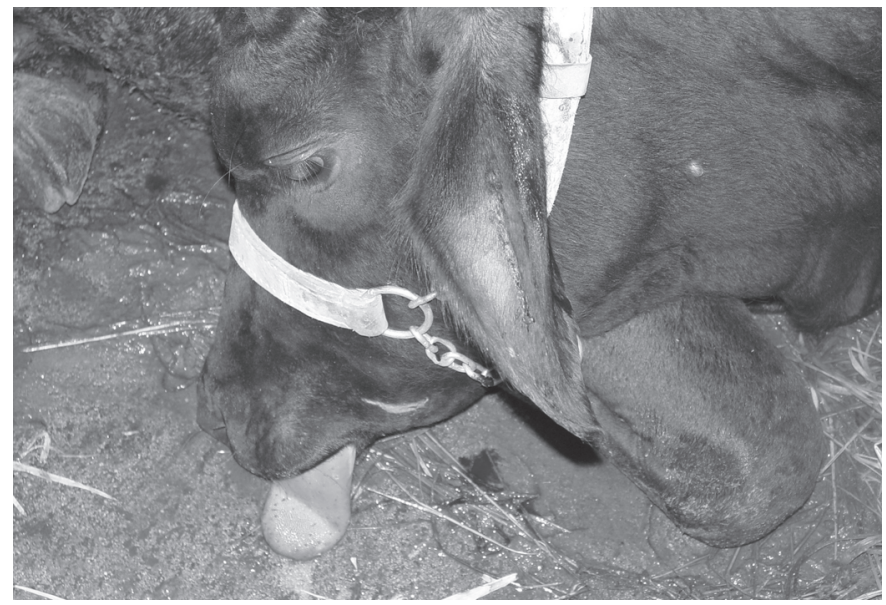

Fig.3. Acentuada diminuição do tônus da língua, o que facilitava sua exteriorização ou dificultava seu recolhimento, além do tempo de sangramento consideravelmente aumentado (Bovino 2). 
diminuiu à medida que se testavam regiões mais caudais do corpo. Foi observada paralisia do globo ocular quando se rotacionava a cabeça na direção latero-caudal através da verificação da exposição parcial da esclera nos animais que receberam doses potencialmente letais de 0,03 e 0,015mg/kg (Fig.2). Este achado clínico permaneceu durante toda a evolução clínica até a morte ou por até três dias após início da recuperação. Pouco depois, ou concomitantemente, os animais apoiavam a cabeça no chão e seguia-se o decúbito lateral. Discreta mioclonia foi observada em apenas dois animais. Dos oito animais cujo quadro evoluiu até o decúbito lateral, seis apresentavam acentuada diminuição do tônus da língua, o que facilitava sua exteriorização ou dificultava seu recolhimento (Fig.3). Com o subseqüente agravamento do caso havia intensa sialorréia, movimentos de pedalagem, protusão do esfíncter anal, acentuada paralisia dos músculos da face, episódios de vocalização e morte. As principais alterações neurológicas encontradas e sua cronologia estão apresentadas no Quadro 2.

\section{Patologia clínica}

$\mathrm{Na}$ avaliação do eritrograma verificou-se apenas discreta hemoconcentação. As plaquetas e os reticulócitos também mantiveram-se dentro dos parâmetros fisiológicos da espécie bovina. Com relação às proteínas séricas totais houve discreta elevação nos Bovinos 4 e 5 . O leucograma evidenciou um moderado aumento da leucometria global em nove dos dez bovinos submetidos à inoculação com veneno crotálico, caracterizado por neutrofilia, linfopenia relativa, eosinopenia e monocitose. Foi verificado um discreto aumento do número de bastões. Na mensuração dos parâmetros bioquímicos séricos dos animais, o Bovino 1, que recebeu a maior dose de veneno crotálico, apresentou um acentuado aumento da concentração de glicose plasmática, seis horas após a inoculação (241,4mg/ dl). Passadas 12 horas da inoculação, foi observada acentuada elevação também no Bovino 9 (365,8mg/dl de glicose plasmática). Nos demais, o aumento da glicemia foi discreto, com exceção do Bovino 2. Todos os animais inoculados apresentaram discreto aumento dos níveis de uréia que variou entre 12,1 e $20,5 \mathrm{mg} / \mathrm{dl}$ no tempo zero e apresentaram valores máximos que variaram entre 36,5 e 39,4mg/dl no decorrer do experimento. Em um dos animais-controle (Bovino 11) também houve aumento da uréia de 14,7 para $31,5 \mathrm{mg} / \mathrm{dl}$, seis horas após a inoculação. Os níveis de creatinina estavam discretamente elevados nos Bovinos 3, 4 e 5. A enzima aspartatoaminotransferase excedeu moderadamente os valores normais durante o experimento nos Bovinos 2, 6 e 7. A alanina aminotransferase ultrapassou os limites normais nos Bovinos 2, $8 \mathrm{e}$ 10. A creatinaquinase aumentou significativamente em todos os dez animais inoculados.

O tempo de sangramento observado no tempo zero variou de 2 a 4 minutos 30 segundos, enquanto 6 horas após inoculação esse tempo foi no mínimo 2 minutos e, no máximo, 8 minutos. Doze horas após a inoculação, o sangramento cessou entre 2 e 7 minutos e, com 24 horas após, entre 3 e 19 minutos. Quarenta e oito horas após a

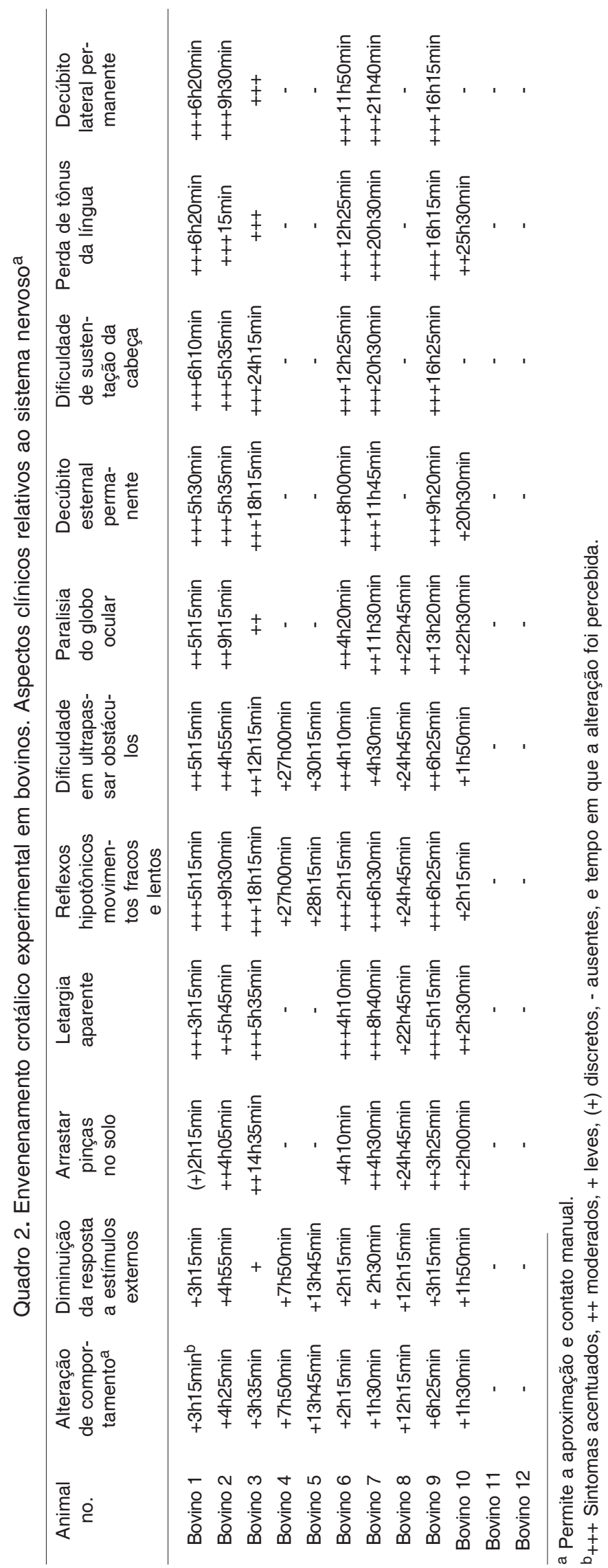

Pesq. Vet. Bras. 28(6):261-270, junho 2008 
inoculação, o tempo de sangramento oscilou entre 3 e 27 minutos (Fig.3). Durante a coleta de sangue para obtenção de soro foi evidente, após 24 horas de inoculação, houve dificuldade em se obter o coágulo.

Observou-se uma discreta diminuição dos níveis de fibrinogênio plasmático nos Bovinos 2, 3, 7, 8 e 10, enquanto no tempo de ativação da protrombina (TAP) não houve variações dignas de nota.

Havia moderado aumento do tempo de tromboplastina parcial ativada (TTPA), a partir de 6 horas após a inoculação nos Bovinos 1, 3, 4, 5, 6 e 7. No Bovino 10, o TTPA aumentou discretamente, 48 horas pós-inoculação. Não foram encontradas alterações significativas no exame de urina dos bovinos envenenados.

\section{Achados de necropsia e histopatológicos}

O Bovino 1 apresentou como única alteração, edema quase imperceptível no local da inoculação, além de discreta sufusão no epicárdio. Os Bovinos 2, 6 e 7 apresentaram também discreto edema com discretas hemorragias no local da inoculação, além de discretas hemorragias subendocárdicas puntiformes, algumas petéquias e equimoses na mucosa da bexiga. O Bovino 3 evidenciou pequena quantidade de líquido no saco pericárdico e fígado levemente amarelado. Nos Bovinos 4 e 5 havia apenas discreto edema no local da inoculação tingido de vermeIho. Nos Bovinos 6 e 7, as alterações macroscópicas observadas foram, petéquias no omento, vesícula biliar, mucosa da bexiga e tecido subcutâneo no local da inoculação. Ao exame histológico foi observado necrose (hialinização) de miócitos em todos os músculos examinados. Esta necrose não era difusa na musculatura, ao contrário, era observada em fibras isoladas uma da outra ou em pequenos grupos de fibras (Fig.4).

\section{DISCUSSÃO}

A inoculação de veneno de Crotalus durissus terrificus produziu um quadro nervoso de paralisia flácida, similar ao observado nos demais estudos experimentais em bo-

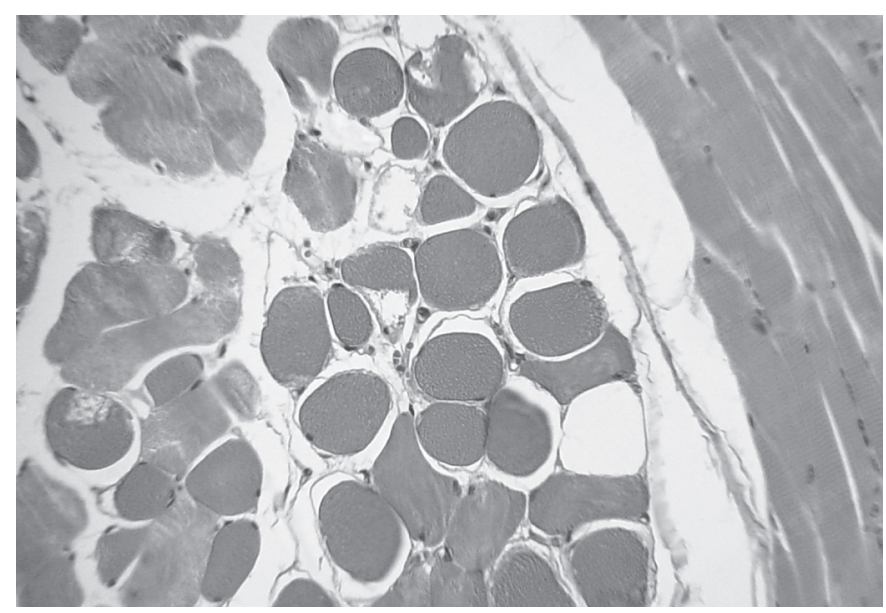

Fig.4. Necrose (hialinização) de miócitos (Bovino 6, SAP 30.284). HE, obj.16x. vinos, realizados no Brasil com veneno de serpentes desse gênero (Araújo et al.1963, Belluomini 1972, Lago 1996). A avaliação criteriosa da literatura revela que há uma tendência a considerarem-se os sintomas e lesões observadas no homem como idênticos ou muito semelhantes aos verificados em bovinos ou em outras espécies animais.

A via e o local de aplicação utilizados no presente estudo foram iguais às descritas por Belluomini (1972) e Lago (1996), porém estes autores consideraram essa forma (via) de inoculação como intramuscular. Levando-se em consideração a espessura da pele do bovino que varia entre três e seis milímetros (Sisson 1986), infere-se que essa aplicação foi sobre a fáscia e pode ser caracterizada como subcutânea.

Optamos por inocular à altura do terço médio do músculo semitendinoso, como forma de evitar a compressão da região inoculada durante o decúbito, o que poderia comprometer a observação da lesão.

Pelo fato de, usualmente, realizarmos experimentos do tipo auto-direcionados, isto é, os resultados do experimento inicial direcionam os experimentos subseqüentes (com o objetivo de diminuir ao máximo o número de animais experimentais), optamos pela dose-base de $0,03 \mathrm{mg} /$ kg (a mesma utilizada por Lago (1996) e inferior à aplicada por Araújo et al. (1963), de 0,05mg/kg. De fato, mesmo com essa dose, evidenciamos um período de evolução muito curto. Como o objetivo principal do trabalho era caracterizar, com precisão, o quadro clínico-patológico do envenenamento crotálico em bovinos, utilizamos, a partir da dose-base, doses menos capazes de induzir uma evolução mais lenta. A dose foi então reduzida à metade $(0,015 \mathrm{mg} / \mathrm{kg})$, o que resultou em quadro mais protraído, embora ainda com letalidade de $57 \%$.

Um dos aspectos principais a serem considerados, diz respeito à capacidade que serpentes do gênero Crotalus podem ter de levar um bovino adulto à morte.

Quatro de sete animais que foram inoculados com $0,015 \mathrm{mg} / \mathrm{kg}$ morreram, o que, de início configura uma dose potencialmente letal menor que a descrita por Araújo et al. (1963) e Rosenfeld \& Belluomini (1960), da ordem de $0,05 \mathrm{mg} / \mathrm{kg}$. Se levarmos em conta essa menor dose letal e a quantidade média de veneno que $75 \%$ das serpentes desse gênero fornecem nas extrações $(50 \mathrm{mg})$, uma cascavel teoricamente poderia levar à morte um bovino de $3333 \mathrm{~kg}$. Portanto, está fora de dúvida que as cascavéis sul-americanas podem levar à morte bovinos de qualquer idade, desde que "desejem" inocular quantidades significativas do seu veneno.

Contudo, é preciso considerar que, há uma significativa incidência dos chamados "botes secos", ou seja, as serpentes, muitas vezes, não inoculam veneno algum através da picada, nesse caso, mera atitude de defesa (Mattingly \& Bosse 2001), uma vez que, provavelmente, a serpente não deve considerar o bovino como uma presa em potencial. De outro lado, a inoculação de veneno constitui uma ação voluntária, sob total controle da vontade do ofídio (Clarke \& Clarke, 1969). 
Da mesma forma que o observado por Lago (1996), para os animais que receberam doses potencialmente letais, os sinais clínicos se iniciaram entre uma hora e meia e quatro horas após a inoculação. Com a dose reduzida à metade (não-letal), a sintomatologia teve início, aproximadamente, entre oito e quatorze horas, isto é, quanto maior a dose, mais rápido este período. Os animais que receberam as doses mais elevadas evidenciaram um quadro muito mais nítido e grave, representado por acentuada diminuição do tônus muscular com decúbito esternal ou lateral permanente, do que aqueles que foram inoculados com doses sub-letais, nos quais clinicamente só foram observadas diminuição do raio de aproximação e da resposta aos estímulos externos e dificuldade em ultrapassar obstáculos. Um quadro clínico discreto como esse poderia passar despercebido a campo ou seria interpretado como uma desordem de natureza inespecífica com cura espontânea. Da mesma maneira que o verificado com o início dos sintomas, também o tempo de evolução foi diretamente proporcional à dose de veneno inoculada ou seja, quanto maior a dose inoculada mais curta foi a evolução clínica.

O interesse pelos alimentos foi, de início, mantido em certa medida, provavelmente enquanto havia tônus nos músculos responsáveis pela apreensão e mastigação, com o agravamento do quadro, o animal passava a interromper a apreensão de alimentos por incapacidade muscular. A moderada hipotonia ruminal poderia ter contribuído para a diminuição do apetite, como já mencionado por Belluomini (1976). Não encontramos menção na literatura à ocorrência de adipsia, por nós verificada em todos os animais deste estudo.

Todos esses sintomas provavelmente estejam relacionados à causa básica geral, ou seja, o comprometimento da neurotransmissão na musculatura responsável pela sucção, mastigação e deglutição.

O fato de a freqüência cardíaca permanecer dentro dos parâmetros fisiológicos, durante a evolução clínica, indica que não ocorreu dor aguda, lesões no músculo cardíaco, ou anemia; também corroboram com essa hipótese os achados laboratoriais.

O edema quase imperceptível e a ausência de lesões verificados no local da inoculação é outro fator que contribui para a dificuldade do diagnóstico clínico. Acreditamos que o edema poderia passar despercebido se o local da inoculação não fosse previamente tricotomizado. Esta ausência de alterações no local da picada também foi descrita em humanos (Amaral et al. 1991).

O aparecimento de petéquias nas mucosas conjuntival do Bovino 2 e vaginal do Bovino 3 pode ter sido causado por distúrbios da coagulação, todavia, não foram considerados importantes ou característicos para o diagnóstico do envenenamento. Esta observação já havia sido feita referente a humanos, por Amaral et al. (1986), Barraviera (1999), Pinho \& Pereira (2001), que relataram quadros de epistaxe e hemorragia gengival ocorrem apenas em $40 \%$ dos casos.

\section{Quadro neurológico}

Através do acompanhamento clínico e da observação da resposta aos testes neurológicos verificamos um quadro sintomatológico caracterizado, principalmente, pela hipotonia muscular generalizada com sintomatologia que, de acordo com a literatura, deve-se à ação pré-sináptica sobre a junção mioneural, a qual resulta em incapacitação muscular difusa ou, em outras palavras, paralisia flácida. Exames sucessivos demonstraram que os bovinos desenvolviam, após a inoculação, dificuldade ou incapacidade de produzir resposta aos estímulos externos, fato esse já explicado pela ação das toxinas encontradas na peçonha crotálica, especificamente a crotoxina (Brazil 1980, Varanda \& Giannini 1999).

Esta hipotonia muscular acentuada e progressiva, nos casos fatais, pode mimetizar alterações do sistema nervoso central, como por exemplo, depressão e letargia relacionadas a lesões difusas na região cortico-cerebral, diminuição de reflexos e déficit proprioceptivo correlacionados ao tronco encefálico, ou ainda paralisia do globo ocular, língua e demais músculos da face ligados aos núcleos dos nervos cranianos (Riet-Corrêa et al. 2002). A hipotonia muscular seria, entretanto, apenas a forma de manifestação clínica resultante da ação pré-sináptica da toxina. Barros et al. (2006) afirmam que face à ausência de um reflexo monossináptico (p.ex. reflexo patelar), com comprometimento apenas da porção motora do sistema nervoso periférico, o bovino não tem reflexo, mas sente dor e, neste caso, devemos considerar ainda a possibilidade de lesões neuromusculares que podem causar, também, debilidade severa nos quatro membros, sem ataxia, espasticidade ou alterações de sistema nervoso central.

Toxinas como a crotamina e girotoxina, parecem ter pouca relação com o quadro clínico observado nos bovinos.

Exames seqüenciais para avaliação dos pares cranianos não detectaram, em nosso experimento, nenhum sinal de acometimento dos seus núcleos, como por exemplo abolição do reflexo pupilar, "fácies neurotóxico de Rosenfeld" e o nistágmo verificados em humanos (Barraviera 1999, Pinho\& Pereira 2001, Bucaretchi et al. 2002), animais de laboratório (Castro 1999) e em cães (Ferreira Júnior \& Barraviera 2004, Nogueira et al. 2004) ou ainda, a ptose palpebral, verificada em alguns experimentos com bovinos (Belluomini et al. 1982, Lago 1996). Por outro lado, constatamos a paralisia do globo ocular, em todos os animais que receberam doses de 0,015 ou $0,03 \mathrm{mg} / \mathrm{kg}$, revelada através da não-exposição da esclera durante a rotação da cabeça no sentido horário e antihorário, alteração descrita por Belluomini et al. (1982) Este achado clínico constitui, ao nosso ver, indicação importante para estabelecimento do diagnóstico e diagnóstico diferencial do envenenamento crotálico em bovinos. Belluomini et al. (1982) verificaram este sintoma em um período compreendido entre seis e 72 horas após a inoculação. 


\section{Patologia clínica}

Com relação aos achados de patologia clínica dos bovinos submetidos ao envenenamento crotálico alguns pontos devem ser discutidos. A discreta hemoconcentração pode ser explicada pela privação de água e ação de prostaglandinas que aumentam no soro e, conseqüentemente, a permeabilidade capilar frente a presença de fosfolipases (Lago et al. 2001). Nesse estudo, a observação de leucocitose caracterizada por discretas neutrofilia, linfopenia, monocitose e eosinopenia indicam apenas um leucograma de estresse, determinado pela migração do "pool" marginal para o meio circulante, induzida pelo aumento da liberação de cortisol endógeno (Jain 1986), por outro lado, em alguns animais, houve discreto aumento no número de bastões e plaquetas, o que poderia indicar leve resposta medular (inflamatória) possivelmente resultado da ação das fosfolipases. Análises bioquímicas de casos isolados de hiperglicemia podem estar ligados ao estresse e ao conseqüente aumento dos níveis de cortisol. Elevação dos níveis de uréia verificada em todos os animais que receberam veneno nesse experimento também foi observada também por Lago et al. (2004). É possível que as condições de adipsia associada ao discreto catabolismo muscular podem ter favorecido essa alteração. Por outro lado, verificamos, durante nosso experimento, que um bovino controle também apresentou aumento dos níveis de uréia, talvez induzido pela constante manipulação do animal e diminuição do consumo de água. Foi observada discreta diminuição dos níveis plasmáticos de fibrinogênio em cinco bovinos, porém, não tão acentuados quanto a encontrada por Lago (1996). As dosagens de creatinaquinase excederam em até dez vezes os valores obtidos no tempo zero, o que está em concordância com as observações de Lago et al. (2004). Por outro lado Radostits et al. (2000) descreveram a síndrome da vaca caída com aumento dos níveis séricos de creatinaquinase acima de cento e cinqüenta vezes os valores normais. Graça et al. (2006) submeteram quatro bovinos ao decúbito experimental por seis horas e verificaram, 18 horas após o início do decúbito, aumentos de creatinaquinase de aproximadamente 130 vezes os valores obtidos antes do início da contenção. Devemos lembrar que além da ação miotóxica, os animais de nosso experimento foram submetidos à contenção mecânica, punções venosas para coleta de sangue e permaneceram em decúbito por períodos que variaram entre 2 horas 10 minutos e 9 dias ou seja, os resultados obtidos em estudos ligados ao decúbito permanente em bovinos, indicam que os valores obtidos em nosso experimento não sugerem um quadro acentuado de necrose muscular, o que é confirmado pela ação seletiva da miotoxina sobre as fibras musculares, verificada histologicamente (Hudelson \& Hudelson 1995b, Salvini et al. 2001).

Esta ausência de mioglobinúria comprova a diferença de sensibilidade entre humanos e bovinos do efeito miotóxico do veneno crotálico. Birgel et al. (1983), por outro lado, verificaram a ocorrência de microhematúria em $60 \%$ dos casos, glicosúria, proteinúria e dificuldade em concentrar a urina.
Foram observadas alterações nos exames que avaliam a coagulação sangüínea. Leve hipofibrinogenemia foi verificada em cinco dos sete animais que receberam a dose de $0,015 \mathrm{mg} / \mathrm{kg}$. O tempo de sangramento aumentou moderadamente em quatro e discretamente em dois animais submetidos ao envenenamento. A alteração da coagulação apenas em parte dos animais submetidos ao envenenamento também foi verificada por Amaral et al. (1986), Thomazini \& Barraviera (1999) e Pinho \& Pereira (2001). De forma diversa ao observado por Lago (1996), não houve alterações significativas no tempo de ativação da protrombina. Acreditamos que esse fato deve-se aos elevados níveis de fibrinogênio presentes no sangue dos bovinos (Jain 1986). A enzima tipo trombina não teria sido capaz de consumir todo o fibrinogênio. O tempo de tromboplastina parcial ativada aumentou moderadamente, o que indica possibilidade de alteração do fator XIII (Fator von Willebrand), ativado pela trombina, e responsável pela estabilização do coágulo de fibrina (Hudelson \& Hudelson 1995b). Este aumento do tempo de tromboplastina parcial ativada nos indica que apenas a via intrínseca e não a via comum foi comprometida. A discreta diminuição dos níveis de cálcio total observada nos Bovinos 1, 2, 3, 5, e 10, talvez esteja correlacionada aos distúrbios da coagulação, já que este é um co-fator importante no processo (Sano-Martins \& Santoro 2003).

\section{Achados de necropsia e histopatológicos}

Nesse estudo, não verificamos, à necropsia, alterações macroscópicas que pudessem caracterizar o diagnóstico do envenenamento crotálico em bovinos. $O$ discreto edema encontrado no local da inoculação, provavelmente, passaria despercebido ao exame clínico e mesmo à necropsia.

Com relação a miotoxicidade, ao exame histológico, verificamos necrose coagulativa de fibras isoladas ou pequenos grupos de fibras em todos os músculos esqueléticos examinados. Este achado, embora não muito pronunciado, nos parece de grande valor para o diagnóstico pósmorte deste envenenamento, de forma que deve ser enfatizada a necessidade de coletar diversos fragmentos de músculos estriados durante a necropsia de bovinos com histórico de paralisia flácida ou ainda de morte com evolução rápida, sem lesões macroscópicas significativas ou de etiologia obscura, sem histórico definido. Esta ação miotóxica em determinadas fibras corrobora as afirmações de (Hudelson \& Hudelson 1995a) e Salvini et al. (2001) sobre a seletividade da ação da crotoxina sobre as fibras musculares tipo I e lla. Segundo Radostits et al. (2000) e Banda et al. (2004), os tipos de fibras musculares esqueléticas I, Ila e Ilb possuem distribuição variada e dependem da base genética, idade e tipo de exercício a que o animal é submetido. É possível que no futuro métodos histoquímicos possam mapear a distribuição dessas fibras e correlacioná-las com as lesões observadas no envenenamento em bovinos.

Um outro aspecto a ser considerado diz respeito a ausência de diferenças na intensidade ou na freqüência 
da necrose coagulativa entre as fibras musculares esqueléticas próximas e distantes do local da inoculação, o que caracteriza uma ação sistêmica da crotamina. Não foi observado em nenhum dos músculos examinados lise de miócitos, o que está de acordo com as observações de Lago (1996), e que, ao nosso ver, poderia explicar a ausência de mioglobina na urina de bovinos intoxicados com veneno crotálico

Em nosso experimento não foram observadas quaisquer alterações histopatológicas nos rins. É difícil precisar qual a causa desta discrepância, mas a leitura atenta do quadro histológico descrito por Saliba et al. (1983), ao nosso ver, não permite a distinção segura entre lesão e autólise. Por outro lado, o achado de infiltração inflamatória mononuclear também descrito por esses autores, mais provavelmente é incidental, já que essa lesão é comum no rim de bovinos e, em princípio, demandar mais tempo para sua instalação, além de, aparentemente, não ter relação com a inoculação do veneno. A semelhança dos achados verificados neste estudo com outras enfermidades, como por exemplo, enfermidades do sistema nervoso central e periférico (sobretudo botulismo) ou que causam necrose muscular (por exemplo deficiência de selênio), demonstram a importância da realização do diagnóstico diferencial. Tokarnia et al. (2002) relataram que, na Região Norte, os numerosos casos de intoxicação por plantas que causam morte súbita, em geral, são atribuídos à "picada-de-cobra", o que, obviamente, superestima a ocorrência de acidentes ofídicos, já que muitos milhares de cabeças morrem anualmente vítimas da intoxicação por Palicourea marcgravii. Além disto, sabe-se, que Crotalus durissus terrificus na Amazônia ocorre somente em algumas áreas abertas de Humaitá, Serra do Cachimbo e Santarém (Melgarejo 2003). Mesmo sabendo-se do potencial de letalidade de uma serpente da espécie $C$. durissus terrificus com relação à quantidade de veneno existente em sua glândula, devemos recordar os estudos de Clarke \& Clarke (1969), Silveira \& Nishioka (1995), Bucaretchi et al. (2002) e Melgarejo (2003), que tratam da relevante ocorrência das chamadas "picadas secas" ou quando apenas parte do veneno é injetada, o que gera incertezas quanto a dose inoculada. A variação da concentração das toxinas em função de idade, peso, alimentação e distribuição geográfica da serpente dificulta ainda mais a referida projeção (Magro et al. 2001, Furtado et al. 2003). A inoculação subcutânea de $0,015 \mathrm{mg} / \mathrm{kg}$ do veneno da Crotalus durissus terrificus é potencialmente letal para bovinos.

\section{REFERÊNCIAS}

Amaral C.F.S., Rezende N.A., Silva O.A., Ribeiro M.M.F., Magalhães R.A., Reis R.J., Carneiro J.G. \& Castro J.R.S. 1986. Insuficiência renal aguda secundária a acidentes ofídicos botrópico e crotálico: análise de 63 casos. Revta Inst. Med. Trop. São Paulo. 28(4):220-227.

Amaral C.F.S., Magalhães R.A. \& Resende N.A. 1991. Comprometimento respiratório secundário a acidente ofídico crotálico. Revta Inst. Med. Trop. São Paulo 33(4):251-255.

Araújo P., Rosenfeld G. \& Belluomini H.E. 1963 Toxicidade de venenos ofídicos. II. Doses mortais para bovinos. Arqs Inst. Biológico, São Paulo, 30:43-48.
Banda T., Dhanapati N., Jin-Bo K.,Ishioroshi M., Katsuji M., Hitoshi C., Tommo Ito. \& Samejima K. 2004. Immunohistological study on bovine, swine and ovine skeletal muscle fibers for the localization of fatty acid translocase FAT/CD36. Anim. Sci. J. 75(2):155-159.

Barraviera B. 1999. Acidentes por serpentes do gênero Crotalus e Micrurus, p.281-295. In: Barraviera B. (ed.), Venenos: Aspectos Clínicos e Terapêuticos dos Acidentes por Animais Peçonhentos. EPUB, Rio de Janeiro.

Barros C.S.L., Driemeier D., Dutra I.S. \& Lemos R.A.A. 2006. Doenças do Sistema Nervoso de Bovinos no Brasil. Coleção Vallée, Agnes, São Paulo. 207p.

Bastos E.G.M., Araújo A.F.B. \& Silva H.R. 2005. Records of the rattlesnakes Crotalus durissus terrificus (Laurenti) (Serpentes, Viperidae) in the State of Rio de Janeiro, Brazil: A possible case of invasion facilitated by deforestation. Revta Bras. Zoologia 22(3):812-815.

Belluomini H.E. 1972. Ensaios soroterápicos no envenenamento crotálico experimental em bovinos. Tese de Doutorado em Ciências Biomédicas, Universidade de São Paulo, São Paulo. 190p.

Belluomini H.E. 1976. O que se deve saber sobre serpentes. Noticioso Rhodia-Mérieux, São Paulo, 5(52):6-16.

Belluomini H.E., Araujo P., Rosenfeld G., Leinz F.F. \& Birgel E.H. 1982. Symptomatologie der experimentellen Crotalustoxin-Vergiftung bei Rindern, die einer spezifischen Serumtherapie unterworfen wurden. Dtsch. Tierärztl. Wochenschr. 89(11):444-448.

Bicudo P.L. 1999. Acidentes ofídicos em Medicina Veterinária, p.375387. In: Barraviera B. (ed.), Venenos: aspectos clínicos e terapêuticos dos acidentes por animais peçonhentos. EPUB, Rio de Janeiro.

Birgel E.H., Belluomini H.E. \& Leinz F.F. 1983. Auswertung der Urinbefunde bei Rindern mit experimenteller Crotalus-Vergiftung. Zbl.Vet. Med. A 30:283-289.

Brazil O.V. 1980. Venenos ofídicos neurotóxicos. Revta Assoc. Méd. Bras., São Paulo, 26(6):212-218.

Bucaretchi F., Herrera S.R.F., Hislop S., Baracat E.C.E. \& Vieira R.J. 2002. Snakebites by Crotalus durissus spp. in children in Campinas, São Paulo. Revta Inst. Med. Trop. São Paulo 44(3):133-138.

Castro K.N.C. 1999. Avaliação funcional e estrutural hepática e comportamental de ratos inoculados com o veneno da cascavel (Crotalus durissus terrificus) e/ou tratados com o extrato do leiteiro (Tabernaemontana catharinensis). Dissertação de Mestrado em Medicina Veterinária, Universidade Estadual Paulista, Jaboticabal. 87p.

Clarke E.G.C. \& Clarke M.L. 1969. Snakes and snakebite. Vet. Annual 1(10):27-48.

Ferreira Júnior R.S. \& Barraviera B. 2004. Management of venomous snakebites in dogs and cats in Brazil. J. Venom. Anim. Toxins 10(2): 112-132.

Furtado M.F.D., Santos M.C. \& Kamiguti A.S. 2003. Age-related biological activity of South American rattlesnake (Crotalus durissus terrificus) venom. J. Venom. Anim Toxins 9(2):186-201.

Graça F.A.S. \& Souza Junior A.A. 2006. Análise sorológica dos níveis séricos de uréia, glicose, creatinofosfoquinase e aspartato aminotransferase em bovinos (Bos taurus) submetidos ao decúbito prolongado. Fac. Med. Vet. UCB, Rio de Janeiro. (Dados não publicados)

Hudelson S. \& Hudelson P. 1995a. Pathophysiology of snake envenenomization and evaluation of treatments - part 1. Comp. Cont. Educ., Lawrenceville, 17(7):889-896.

Hudelson S. \& Hudelson P. 1995b. Pathophysiology of snake envenenomization and evaluation of treatments - part 2. Comp. Cont. Educ., Lawrenceville, 17(8):1035-1040.

Jain N.C. 1986. Schalm's Veterinary Hematology. 4th ed. Lea and Febiger, Philadelphia. 1221p.

Lago L.A. 1996. Avaliação clínica e laboratorial de bovinos submetidos ao envenenamento crotálico experimental (Crotalus durissus terrificus, Laurenti, 1768) crotamina positivo. Dissertação de Mestrado em Me- 
dicina Veterinária, Universidade Federal de Minas Gerais, Belo Horizonte. $86 p$.

Lago L.A., Melo M.M., Ferreira P.M. \& Facury Filho E.J. 2001. Alterações hematológicas em bovinos submetidos ao envenenamento crotálico. Revta Bras. Saúde Prod. Anim.1(1):7-13.

Lago L.A., Marques Junior A.P., Melo M.M., Lago E.P., Oliveira N.J.F. \& Alzamora Filho F. 2004. Perfil bioquímico sorológico de bovinos inoculados experimentalmente com veneno crotálico iodado livre e iodide incorporado em lipossomes. Arq. Bras. Med. Vet. Zootec. 56(5):653-657.

Magro A. J., Da Silva R.J., Ramos P.R.R., Cherubini M.R. \& Hatayde M.R. 2001. Intraspecific variation in the venom electrophoretic profile of recently captured Crotalus durissus terrificus (Lurenti, 1768) snakes. J. Venom. Anim. Toxins 7(2):276-301.

Mattingly J. \& Bosse G. 2001. Snakebite in the state of Kentucky: Cotalid envenomation. Disponível em: <http://www.krpc.com/proffed/ snake\%5CSnakebite.cfm>. Acesso em: 16 fev. 2007.

Melgarejo A.F. 2003. Serpentes peçonhentas do Brasil, p.33-61. In: Cardoso J.L.C., França F.O.S., Wen F.H., Málaque C.M.S. \& Haddad Jr V. (ed.), Animais Peçonhentos do Brasil: biologia, clínica e terapêutica dos acidentes. Sarvier Editora, São Paulo.

Nogueira R.M.B., Sakate M. \& Barros G.C. 2004. Acidente crotálico em animais domésticos. Revta CFMV, Brasília, 10(31):47-66.

Pacheco G. \& Carneiro V. 1932. Estudos experimentais sobre plantas tóxicas. I. Intoxicação dos animais pela "erva de rato da mata". Revta Soc. Paulista Med. Vet. 1(2):23-46.

Pinho F.M.O. \& Pereira I.D. 2001.Ofidismo. Revta Assoc. Méd. Bras. 47(1):24-29.

Radostits E.M., Gay C.C., Blood D.C. \& Hinchcliff K.W. 2000. Veterinary Medicine. 9th ed. W.B. Saunders, New York. 1877p.

Riet-Correa F., Riet-Correa G. \& Schild A.L. 2002. Importância do exame clínico para o diagnóstico das enfermidades do sistema nervoso em ruminantes e eqüídeos. Pesq. Vet. Bras. 22(4):161-168.
Rosenfeld G. \& Belluomini H.E. 1960. Quantidades de veneno encontrado em serpentes venenosas do Brasil: dados comparativos para avaliação da mortalidade humana (Resumo). 1ํ Congr. Bras. Zoologia, Museu Nacional, Rio de Janeiro. (Cit. Belluomini 1976)

Saliba A.M., Belluomini H.E. \& Leinz F.F.1983. Experimentelle CrotalusVergiftung bei Rindern: Anatomisch-pathologische Studie. Dtsch. Tierärztl. Wochenschr. 90:513-517.

Salvini T.F., Amaral A.C., Miyabara E.H., Turri J.A.O., Danella P.M. \& Seliestre de Araújo H.S. 2001. Systemic skeletal muscle necrosis induced by crotoxin. Toxicon 39(8):1141-1149.

Sano-Martins I.S. \& Santoro M.L. 2003. Distúrbios hemostáticos em envenenamentos por animais peçonhentos do Brasil, p.289-309. In: Cardoso J.L.C., França F.O.S., Wen F.H., Málaque C.M.S. \& Haddad Jr V. (ed.), Animais Peçonhentos no Brasil: Biologia, clínica e terapêutica dos acidentes. Sarvier, São Paulo.

Silveira P.V.P. \& Nishioka S.A. 1995. Venomous snake bite without clinical envenoming ("dry-bite"): A neglected problem in Brazil. Trop. Geogr. Med. 47(2):82-85.

Sisson S. 1986. Tegumento comum, p.1131-1134. In: Getty R. (ed.), Anatomia dos Animais Domésticos. 5aㅡ ed. Guanabara Koogan, Rio de Janeiro.

Thomazini I.A. \& Barraviera B. 1999. Alterações hematológicas nos acidentes por animais peçonhentos, p.81-89. In: Barraviera B. (ed.), Venenos: Aspectos clínicos e terapêuticos dos acidentes por animais peçonhentos. EPUB, Rio de Janeiro.

Tokarnia C.H., Döbereiner J. \& Peixoto P.V. 2002. Poisoning plants affecting livestock in Brazil. Toxicon 40(12):1635-1660.

Tokarnia C.H. \& Peixoto P.V. 2006. A importância dos acidentes ofídicos como causa de mortes em bovinos no Brasil. Pesq. Vet. Bras. 26(2):5568.

Varanda E.A. \& Giannini M.J.S.M. 1999. Bioquímica de venenos de serpentes, p.205-223. In: Barraviera B. (ed.), Venenos: aspectos clínicos e terapêuticos dos acidentes por animais peçonhentos. EPUB, Rio de Janeiro. 